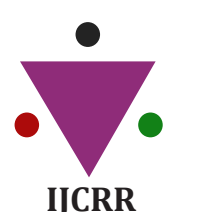

IJCRR

Section: Healthcare

Sci. Journal Impact

Factor: 6.1 (2018)

ICV: 90.90 (2018)

(c) (7) (3)

Copyright@IJCRR

\title{
Gellan Gum Assisted Fabrication and Characterization of Donepezil Hydrochloride Mucoadhesive Intranasal Microspheres
}

\author{
Purushottam S. Gangane ${ }^{1}$, Neha V. Ghormare ${ }^{1}$, Debarshi Kar Mahapatra², \\ Nilesh M. Mahajan' ${ }^{1}$ \\ 'Department of Pharmaceutics, Dadasaheb Balpande College of Pharmacy, Nagpur 440037, Maharashtra, India; 'Department of \\ Pharmaceutical Chemistry, Dadasaheb Balpande College of Pharmacy, Nagpur 440037, Maharashtra, India.
}

\section{ABSTRACT}

Background: Alzheimer's disease is the main reason for dementia among the older section of the community. Administration of drugs through oral route to the patients suffering from neurological disorders is a serious challenge. Intranasal pharmacotherapeutics is an integral part of the modern drug delivery module used as an alternative way due to several therapeutic advantages.

Objective: The objective of this current research was to develop intranasal mucoadhesive microspheres of anti-Alzheimer's drug donepezil $\mathrm{HCl}$.

Methodology: The formulations were prepared using gellan gum polymer in various drug: polymer ratios from 1:1 to 1:4 by emulsification cross-linking technique with an intention to enhance the onset of action, increase the drug bioavailability, and also to overcome the major obstacle blood-brain barrier. The prepared mucoadhesive microspheres were evaluated in terms of drug loading, entrapment efficiency, ex vivo drug permeation, histopathological characteristics, in vitro drug release, in vitro mucoadhesion, morphology, particle size, production yield, and swelling property. The prepared intranasal microspheres were characterized by differential scanning calorimetry, scanning electron microscopy, and X-ray diffraction study.

Result: The fabricated intranasal microspheres had good spherical nature and excellent swelling property with entirely smooth surfaces. After reaching the nasal mucosa, the mucoadhesive microspheres formulations come in contact with the nasal fluid (containing cations), spontaneous viscous gelation (decreases the clearance rate) occurs in the nasal cavity, and the activity enhances several-folds by elevating the residence duration.

Conclusion: This study opened new avenues for enhancing the pharmaceutical efficacy of donepezil $\mathrm{HCl}$ in Alzheimer's patient through intranasal route.

Key Words: Donepezil, Intranasal, Mucoadhesive, Microsphere, Drug absorption, Bioavailability

\section{INTRODUCTION}

Alzheimer's disease is the main reason for dementia among the older section of the community. ${ }^{1}$ The most imperative approach for treating the symptoms of Alzheimer's disease includes augmentation of the amount of cholinergic levels in the brain by specifically obstructing the activity of the enzyme accountable for splitting acetylcholine (the most vital neurotransmitter). ${ }^{2}$ This is mostly accomplished by the class of drugs known as the cholinesterase inhibitors, of which donepezil is an active and well-known member. ${ }^{3}$ Donepezil $\mathrm{HCl}$ is a potent and specific non-competitive in vivo inhibitor of acetylcholinesterase. In human erythrocytes, the drug inhibits the enzyme acetylcholinesterase and enhances the extracellular level of acetylcholine in hippocampus and cerebral cortex of rats. ${ }^{4}$ In experimental animal models, donepezil displayed effectiveness in context to the reference memory, however, it has very less reliable activity in reference to working memory. ${ }^{5}$ It is explicitly recommended in the case of vascular dementia, cognitive impairment, etc in the dose of $5 \mathrm{mg} /$ day or $10 \mathrm{mg}$ /day. The most common known adverse events include gastrointestinal system (nausea, vomiting, gastric upset, constipation, and diarrhea), and nervous system (dizziness). ${ }^{6}$

Intranasal pharmacotherapeutics is an integral part of the modern drug delivery module used as an alternative way due to several therapeutic advantages. ${ }^{7}$ The human nasal mucosa

Corresponding Author:

Purushottam S. Gangane, PhD, Associate Professor, Department of Pharmaceutics, Dadasaheb Balpande College of Pharmacy, Nagpur 440037, Maharashtra, India; Email: p.gangane@gmail.com

ISSN: 2231-2196 (Print)

Received: 15.06 .2020
ISSN: 0975-5241 (Online)

Revised: 12.08 .2020
Accepted: 25.09 .2020
Published: 06.10 .2020 
and mucosa present in several regions in the human body such as vaginal cavities, buccal, gastrointestinal tract, etc. offer a very high surface area which provides a greater permeability that facilitates swift systemic absorption of the drug and fast initiation of drug action. ${ }^{8}$ The mucosa of the nasal cavity is enriched with blood vasculature which leads to direct systemic circulation with results in complete avoidance of hepatic metabolism, and thus enhancement in systemic bioavailability of drugs. ${ }^{9}$

The nasal cavity offers rapid absorption of several imperative drugs as compared to the oral route. ${ }^{10}$ Administration of drugs through oral route (tablets, capsules, elixirs, and syrups) to the patients suffering from neurological disorders (Alzheimer's disease, Parkinson's disease, psychosis, etc.) is a serious challenge. ${ }^{11}$ Nasal administration of very finely distributed powdered drug-loaded intranasal mucoadhesive microspheres results in swelling of formulation in presence of water and immediately forms a gel constituency that reduces the clearance rate from the mucosal cavity and eventually leads to a higher retention of formulation in the nasal cavity and releases drug for a prolong period of time to the brain via nose to brain pathway..$^{12}$ After the administration of intranasal microspheres, the nasal mucosa gets dehydrated due to the rapid uptake of moisture by the microspheres. This causes reversible contraction of the cells which provides a provisional gaping of the taut junctions that enhances the absorption of drugs..$^{13}$

In general, emulsification cross-linking technique is a significant procedure for the preparation of microspheres due to high feasibility, easy scale-up, excellent drug loading ability, and good laboratory-scale reproducibility as compared to the other prevalent techniques of microsphere development. ${ }^{14}$ The objective of this current research was to develop intranasal mucoadhesive microspheres of anti-Alzheimer's drug donepezil $\mathrm{HCl}$ using gellan gum polymer in various drug: polymer ratios from $1: 1$ to $1: 4$ by emulsification cross-linking technique with an intention to enhance the onset of action, increase the drug bioavailability, and also to overcome the major obstacle blood-brain barrier. The prepared mucoadhesive microspheres were evaluated in terms of drug loading, entrapment efficiency, ex vivo drug permeation, histopathological characteristics, in vitro drug release, in vitro mucoadhesion, morphology, particle size, production yield, and swelling property. The prepared intranasal microspheres were characterized by differential scanning calorimetry, scanning electron microscopy, and $\mathrm{X}$-ray diffraction study.

\section{MATERIALS AND METHODS}

\section{Materials}

Pharmaceutical grade donepezil $\mathrm{HCl}$ and gellan gum were procured from Cipla ${ }^{\circledR}$ India Limited, Mumbai, India. Loba
Chem ${ }^{\circledR}$ Limited, Mumbai, India supplied analytical grade calcium chloride, Span-80, n-octanol, and dichloromethane. All other solvents, chemicals, and reagents employed in the experimentation were of analytical grade and procured through a local vendor at Nagpur, India. Double distilled water (Borosil®, Mumbai, India) was utilized for the study.

\section{Instruments}

Mechanical stirrer (Remi ${ }^{\circledR}$ Laboratory Limited., Mumbai, India), Digital Motic microscope (DMW2-223, Motic ${ }^{\circledR}$ Instruments Inc., Canada), Franz Diffusion Cell (Orchid Scientific ${ }^{\circledR}$, Nashik, India), pH meter (Labtronics ${ }^{\circledR}$ LT-10, New Delhi, India), Weighing balance (Wensar Weighing Scales Limited, India), Rotary shaker (Biotechniques ${ }^{\circledR}$ BIP05B, India), Magnetic stirrer (Remi ${ }^{\circledR}$ Laboratory Limited, Mumbai, India), Sonicator (PCI analytical 100HPOTC, India), UV/Vis spectrophotometer (Shimadzu ${ }^{\circledR}$ UV-1800, Japan), Fourier transform infrared spectroscopy (GX-FT-IR, Perkin Elmer ${ }^{\circledR}$, USA), Scanning electron microscopy (Jeol ${ }^{\circledR}$, JSM5610 LV, Japan), X-ray diffraction (Ultima-III, Rigaku ${ }^{\circledR}$, Japan), Differential scanning calorimetry (Mettler Toledo $\AA$, USA), USP Dissolution 33 (Type-II) apparatus (Electrolab $®$, Mumbai, India), and Hot air oven (Biotechniques ${ }^{\circledR}$ Limited, India) were employed for formulating the microspheres and their characterization functions.

\section{Drug and polymer interaction studies}

The drug and polymer compatibility study was conducted between donepezil $\mathrm{HCl}$ and polymer gellan gum using a FTIR spectrometer to check the suitability of polymer for the preparation of microsphere. The samples (drug, polymer, and physical mixture) were prepared into the $\mathrm{KBr}$ disks and scanning was performed in the range of 4000 to $500 \mathrm{~cm}^{-1} .{ }^{15}$

\section{Preparation of mucoadhesive microsphere}

Mucoadhesive microspheres were prepared by w/o emulsification cross-linking technique. The w/o emulsification cross-linking technique is one of the most prevalent preparation techniques used extensively for developing the therapeutic microspheres. There are basically two systems from which to choose: oil-in-water $(\mathrm{o} / \mathrm{w})$ or water-in-oil (w/o) emulsions. The o/w emulsions are more widely used for water-insoluble drugs. For the present study, w/o emulsion was employed as donepezil $\mathrm{HCl}$ is very soluble in double-distilled water. So, in the present investigation, the inorganic solvent was used as a polar phase (representing the aqueous phase) to form w/o type of emulsion system. The mucoadhesive polymer gellan gum was made to crosslink with $\mathrm{CaCl}_{2}$ solution for the preparation of intranasal mucoadhesive microspheres. These polymers were employed for the fact that they possess good biocompatibility, are non-irritant, and non-toxic. Gellan gum can prolong the residence time of drugs at the absorption site due to their 
desirable mucoadhesive property.

Gellan gum was dissolved in the double-distilled water by gentle heating. Donepezil $\mathrm{HCl}$ was dispersed uniformly in the gellan gum solution with constant agitation at $40^{\circ} \mathrm{C}$ temperature and then, the weighed amount of drug was added to the above gellan gum homogeneous solution. The above solution was quickly injected using a $5 \mathrm{~mL}$ syringe into 100 $\mathrm{mL}$ of $\mathrm{n}$-octanol: water system (99:1 ratio) containing $2 \%$ $\mathrm{w} / \mathrm{v}$ span-80 in a $250 \mathrm{~mL}$ beaker with constant agitation at $1700 \mathrm{rpm}$ using a mechanical stirrer. The w/o emulsion was stirred for $30 \mathrm{~min} .4 \% \mathrm{CaCl}_{2}$ solution was then added dropwise and then dispersion was agitated for the duration of 5 min. The prepared microspheres were then filtered through the Whatman filter paper no. 41 and washed 2-3 times thoroughly with isopropyl alcohol. The microspheres were then dried in a hot air oven at $40^{\circ} \mathrm{C}$ temperature and stored in a desiccator at room temperature. The formulation chart is given in Table 1.

\section{Evaluation of mucoadhesive microspheres}

\section{Production yield}

The production yield of various microsphere formulation batches was determined by calculating the percentage of weight obtained after drying the final product (formulation) with respect to the initial weight of donepezil $\mathrm{HCl}$ and gellan gum polymer. ${ }^{16}$

$$
\% \text { Production yield }=\frac{\text { Practical } \text { mass }(\text { final product })}{\text { Theoretical } \text { mass }(\text { polymer }+ \text { drug })} \times 100
$$

\section{Drug loading}

The weighed amount of donepezil $\mathrm{HCl}$ in the microsphere of each formulation was extracted in double distilled water on a mechanical shaker for $24 \mathrm{hrs}$ duration to extract the entrapped drug completely. The solution was filtered through Whatman filter paper no. $41.1 \mathrm{~mL}$ of this solution was withdrawn and diluted to $10 \mathrm{~mL}$ with double distilled water. This

Table 1: Formulation batches of gellan gum microspheres of donepezil HCl.

\begin{tabular}{lcccc}
$\begin{array}{l}\text { Formulation } \\
\text { code }\end{array}$ & $\begin{array}{c}\text { Drug } \\
(\mathrm{mg})\end{array}$ & $\begin{array}{c}\text { Gellan gum } \\
(\mathbf{m g})\end{array}$ & $\begin{array}{c}\text { Polymer } \\
\text { ratio }(\mathbf{w} / \mathrm{w})\end{array}$ & $\begin{array}{c}\text { Stirring } \\
\text { speed (rpm) }\end{array}$ \\
$\mathbf{N}_{1}$ & 200 & 200 & $1: 1$ & 1700 \\
$\mathrm{~N}_{2}$ & 200 & 400 & $1: 2$ & 1700 \\
N3 $_{3}$ & 200 & 600 & $1: 3$ & 1700 \\
N4 $_{4}$ & 200 & 800 & $1: 4$ & 1700 \\
\hline
\end{tabular}

solution was assayed for the drug content by UV spectrophotometer at $314 \mathrm{~nm} .{ }^{16}$

$\%$ Drug loading $=\frac{\text { Actual amount of drug loaded in microspheres }}{\text { Weighed quantity of microspheres }} \times 100$

\section{Entrapment efficiency}

The weighed amount of donepezil $\mathrm{HCl}$ in the microsphere of each formulation was extracted in double distilled water on a mechanical shaker for $24 \mathrm{hrs}$ duration to extract the entrapped drug completely. The solution was filtered through Whatman filter paper no. $41.1 \mathrm{~mL}$ of this solution was withdrawn and diluted to $10 \mathrm{~mL}$ with double distilled water. This solution was assayed for the drug content by UV spectrophotometer at $314 \mathrm{~nm} .{ }^{16}$

$$
\% \text { Entrapment efficiency }=\frac{\text { Mactual }}{\text { Mtheoretical }} \times 100
$$

Where Mactual is the actual drug content in a weighed quantity of powder of microspheres and theoretical amount of drug in microspheres calculated from the quantity added in the fabrication process is Mtherotical.

\section{Particle size analysis}

For the determination of particle size, a microscopic image analysis technique was utilized by a Motic digital mi- croscope set with a 1/3" CCD camera imaging accessory as well as computer-controlled image analysis software. The prepared microspheres were suitably dispersed on a microscope slide of standard dimension and the microscopic field was scanned by a video camera. The software analyzed the images that lie within the scanned field. ${ }^{16}$

\section{Degree of swelling}

The swellability of the donepezil $\mathrm{HCl}$ microspheres in the physiological media was determined by allowing the formulations to swell in the phosphate buffer $\mathrm{pH}$ 6.6. An accurately weighed amount of microspheres was immersed in little excess of phosphate buffer $\mathrm{pH} 6.6$ for $24 \mathrm{hr}$ duration and washed thoroughly. The degree of swelling was calculated using the following formula ${ }^{16}$ :

$$
\begin{gathered}
\alpha=(\text { Ws-Wo }) / \mathrm{Ws} \\
I=\alpha \times 100
\end{gathered}
$$

Where, $\alpha=$ degree of swelling; Ws = weight of microspheres after swelling; Wo = initial weight of microspheres; and I = $\%$ swelling index.

\section{In-vitro mucoadhesive study}

For determining the mucoadhesive property of the prepared microspheres, falling liquid film technique was employed. 2 
$\mathrm{cm}^{2}$ area of freshly cut goat nasal mucosa was taken from a recently sacrificed goat and thoroughly cleaned with isotonic saline solution. $100 \mathrm{mg}$ of microsphere was placed carefully on a mucosal surface which was attached over a polyethylene plate. The simulated nasal electrolyte solution $(100 \mu \mathrm{L})$ was added to the microspheres and the content was incubated for 15 min duration in a desiccator at $90 \%$ relative humidity to make the gellan gum (polymer) to interact with the nasal mucosa membrane. The membrane was fixed finally at a $45^{\circ}$ angle relative to the horizontal plane. The phosphate buffer of $\mathrm{pH} 6.6$, previously warmed at a temperature of $37 \pm 5^{\circ} \mathrm{C}$ was circulated all over the prepared microspheres and membrane at the rate of $1 \mathrm{ml} / \mathrm{min}$. After $1 \mathrm{hr}$ duration, the amount of drug in the collected perfusate was spectrophotometrically determined. The weight of washed-out microspheres was estimated and the percentage mucoadhesion was computed by the following formula ${ }^{16}$ :

$$
\% \text { in vitro mucoadhesion }=\frac{\text { amount of washout drug in perfusate }}{\text { amount of applied drug in microspheres }} \times 100
$$

\section{Differential scanning calorimetry (DSC)}

The thermal behavior of the pure drug, polymer, physical mixture, and optimized microsphere formulation were studied using a differential scanning calorimeter by heating the samples over a temperature range $30-300^{\circ} \mathrm{C}$ at a heating rate of $10^{\circ} \mathrm{C} / \mathrm{min}$ under an inert nitrogen atmosphere flushed at a rate of $20 \mathrm{~mL} / \mathrm{min}^{17}$

\section{X-Ray diffraction study (XRD)}

The pure drug, polymer, physical mixture, and optimized formulation were studied for X-ray diffraction patterns on a X-ray diffractometer by irradiating $(40 \mathrm{kV}, 35 \mathrm{~mA})$ the samples with $\mathrm{Cu}-\mathrm{K} \alpha$ radiation (monochromatized) in the $2 \theta$ range of $3-60^{\circ} .{ }^{18}$

\section{Scanning electron microscopy (SEM)}

The microspheres were analyzed for their surface morphology under both 400x and 2000x magnifications under a scanning electron microscope. The surface morphology was determined by powdering the gold-coated $\left(4 \mathrm{~A}^{\circ}\right.$ thickness) microspheres over the double-sided tape placed on the aluminum stub of the SEM chamber system. The photomicrographs of the developed microspheres were taken at an operational accelerating voltage of $6 \mathrm{kV} .^{19}$

\section{In-vitro drug release study}

Glass-fabricated Franz diffusion cell was employed for the in vitro drug release study of the fabricated microspheres. The diffusion barrier of the dialysis membrane was employed which had a molecular cut-off $12,000-14,000$. The dialysis membrane was equilibrated by cautiously dispersing the fabricated mucoadhesive microspheres into the donor compartment. The phosphate buffer solution of $\mathrm{pH} 6.6$ (pH range closer to the nasal cavity) was filled into the receptor compartment. The donor compartment was kept in a way that it comes in contact with the receptor compartment containing the diffusion medium. The circulating water bath helped in maintaining the temperature of $37 \pm 1^{\circ} \mathrm{C}$. From the receptor compartment, the samples were withdrawn periodically and the sink condition was maintained. The samples were analyzed at $314 \mathrm{~nm}$ in the UV spectrophotometer. ${ }^{20}$

\section{Drug release kinetics}

To study the release kinetics of donepezil $\mathrm{HCl}$ intranasal mucoadhesive batches, the data obtained from ex vivo drug release studies were plotted in a variety of kinetic models ${ }^{21}$, where:

Zero-order is represented as the rate of the cumulative amount of drug released (Equation 1)

$$
\mathbf{C}=\mathbf{K}_{\mathbf{0}} \mathbf{t}
$$

where $\mathrm{K}_{0}$ is the zero-order rate constant expressed in units of concentration/ time and $t$ is the time in minutes. A graph of concentration vs. time would yield a straight line with a slope equal to $\mathrm{K}_{0}$ and intercept the origin of the axes.

First-order is presented as the rate of Log cumulative $\%$ of remaining drug (Equation 2)

$$
\log C=\log C_{0}-K_{t} / 2.303
$$

where $\mathrm{C}_{0}$ is the initial concentration of the drug, $\mathrm{K}$ is the first order constant and $t$ is the time.

Higuchi's model is depicted as the squared rate of cumulative $\%$ of drug released (Equation 3)

$$
Q_{t}=K_{t}^{1 / 2}
$$

where $Q_{t}$ is the amount of drug release in time $t, K$ is the kinetic constant and $t$ is the time in minutes.

Korsmeyer-Peppas exponential model is Log rate of $\log$ cumulative percentage of drug released (Equation 4).

$$
\mathbf{M t}=\mathbf{M 1} 1 / \mathbf{K t}^{\mathrm{n}}
$$

The release exponent $\mathrm{n}$ and $\mathrm{K}$ value were calculated through the slope of the straight line. If the exponent $n=0.43$ then the drug release mechanisms Fickian diffusion, if $0.43<\mathrm{n}<0.85$ then it is non-Fickian or anomalous diffusion, if $\mathrm{n}<0.85$ mechanism is non-Fickian case-II diffusion.

\section{Ex-vivo permeation study}

Glass-fabricated Franz diffusion cell was employed for the ex vitro drug release study of the fabricated microspheres. The diffusion barrier of goat nasal mucosa was employed. 
The goat nasal mucosa was equilibrated by cautiously dispersing $10 \mathrm{mg}$ of fabricated mucoadhesive microspheres into the donor compartment. The phosphate buffer solution of $\mathrm{pH}$ 6.6 ( $\mathrm{pH}$ range closer to the nasal cavity) was filled into the receptor compartment. The donor compartment was kept in a way that it comes in contact with the receptor compartment containing the diffusion medium. The circulating water bath helped in maintaining the temperature of $37 \pm 1^{\circ} \mathrm{C}$. From the receptor compartment, the samples were withdrawn periodically and the sink condition was maintained. The samples were analyzed at $314 \mathrm{~nm}$ in the UV spectrophotometer. ${ }^{22}$

\section{Histopathology study}

The freshly cut goat nasal mucosa was taken from a recently sacrificed goat, obtained from a local slaughter house and thoroughly cleaned with isotonic saline solution. Donepezil $\mathrm{HCl}$ microspheres were applied to the nasal mucosa for the duration of $1 \mathrm{hr}$ and the nasal mucosa was fixed carbonate buffered formalin solution (10\%, $\mathrm{pH} 7.0)$. The content was processed and embedded in paraffin (to facilitate optimal conditions for tissue viability). $7 \mathrm{~mm}$ of paraffin section was cut over a glass slide and stained with hematoxylin dye and eosin dye. Under a light microscope, the sections were examined and any damage occurred by the drug-loaded intranasal mucoadhesive microspheres during in vitro permeation study was detected. ${ }^{23}$

\section{RESULTS AND DISCUSSION}

\section{Drug-polymer compatibility study}

The possible interaction between the pure drug and the polymer was studied by FTIR spectroscopy. The principal FTIR peaks of the pure donepezil $\mathrm{HCl}\left(3726 \mathrm{~cm}^{-1}, 3526 \mathrm{~cm}^{-1}, 2362\right.$ $\mathrm{cm}^{-1}, 1697 \mathrm{~cm}^{-1}$, and $1265 \mathrm{~cm}^{-1}$ ) (Figure 1A), polymer gellan gum $\left(3593 \mathrm{~cm}^{-1}, 2358 \mathrm{~cm}^{-1}, 1697 \mathrm{~cm}^{-1}, 1269 \mathrm{~cm}^{-1}, 1174 \mathrm{~cm}^{-1}\right.$, $632 \mathrm{~cm}^{-1}$, and $395 \mathrm{~cm}^{-1}$ ) (Figure 1B), physical mixture (3587 $\mathrm{cm}^{-1}, 2358 \mathrm{~cm}^{-1}, 1683 \mathrm{~cm}^{-1}, 1645 \mathrm{~cm}^{-1}, 1589 \mathrm{~cm}^{-1}, 1361 \mathrm{~cm}^{-1}$, $1313 \mathrm{~cm}^{-1}, 1265 \mathrm{~cm}^{-1}, 896 \mathrm{~cm}^{-1}$, and $453 \mathrm{~cm}^{-1}$ ) (Figure 1C), and optimized formulation $\mathrm{N} 2\left(3668 \mathrm{~cm}^{-1}, 2358 \mathrm{~cm}^{-1}, 1697\right.$ $\mathrm{cm}^{-1}, 1267 \mathrm{~cm}^{-1}, 1220 \mathrm{~cm}^{-1}, 1178 \mathrm{~cm}^{-1}, 773 \mathrm{~cm}^{-1}$, and 669 $\mathrm{cm}^{-1}$ ) (Figure 1D) were recorded. The spectra of physical
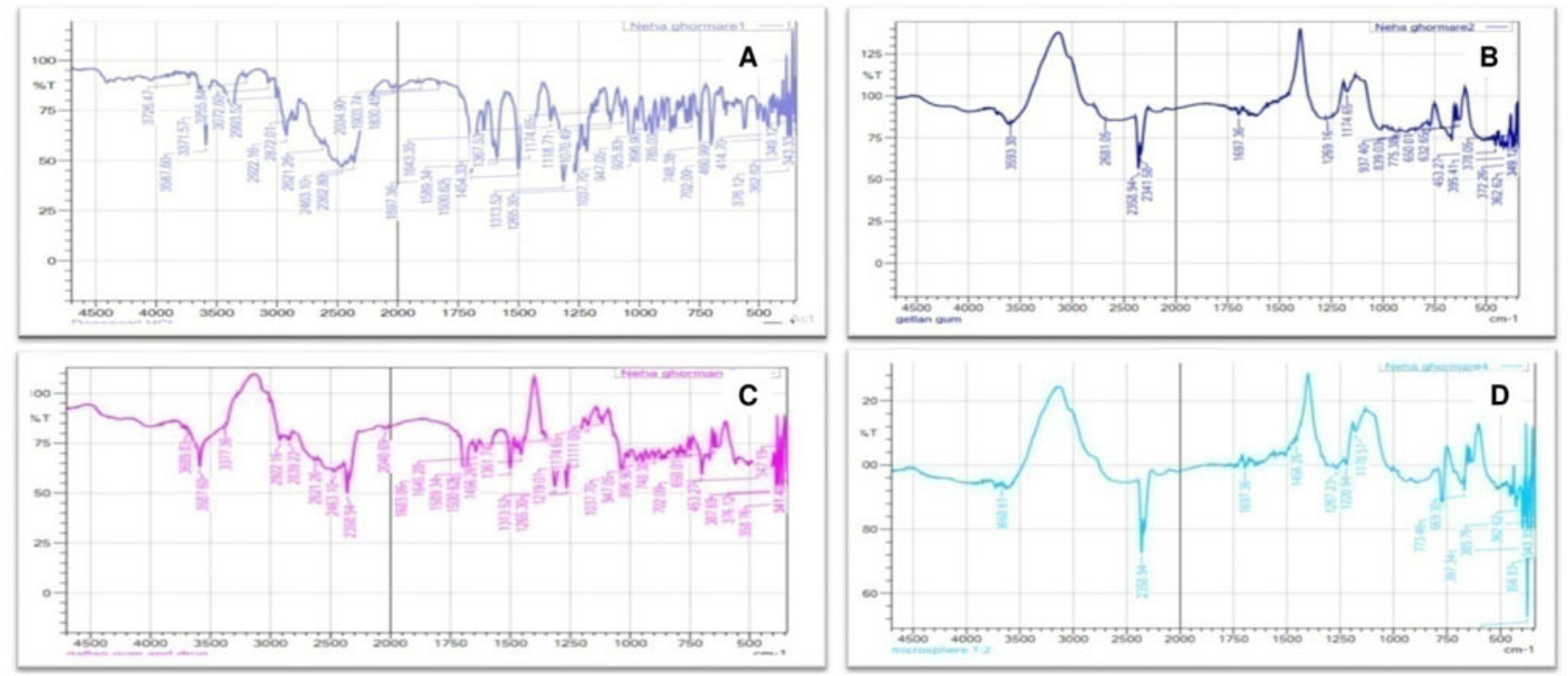

Figure 1: Drug compatibility studies: (A) pure donepezil $\mathrm{HCl}$; (B) gellan gum; (C) physical mixture; and (D) optimized formulation N2.

mixture and the optimized formulation represented nearly similar peaks of pure drug as well as polymeric peaks which concluded no prominent drug interaction between the drug and the polymer, thereby representing high drug-polymer compatibility.

\section{Characterization of intranasal mucoadhesive microspheres}

The prepared mucoadhesive microsphere formulations (N1-N4) were evaluated in terms of drug loading, entrapment efficiency, ex vivo drug permeation, histopathological characteristics, in vitro drug release, in vitro mucoadhesion, morphology, particle size, production yield, and swelling property. The prepared intranasal microspheres were characterized by differential scanning calorimetry, scanning electron microscopy, and X-ray diffraction study.

\section{Production yield}

The production yield of intranasal donepezil $\mathrm{HCl}$ mucoadhesive microspheres was found to be in the range of $40.26 \%$ to $55.93 \%$, respectively (Table 2). It was observed that with an increasing concentration of the polymer, a slight increase in the yield resulted. 


\section{Drug loading}

The drug loading of developed mucoadhesive microspheres was observed to be in the range of $49.21 \%$ to $74.60 \%$ (Table 2). The drug loading was found to be highest in the formulation having the ratio of $1: 1$ as compared to formula- tion containing ratio of 1:4 because with an increase in the concentration of polymer, the morphology of the fabricated microsphere increases and simultaneously, the surface area of the microspheres decreases which results in a decreased drug loading into the formulation.

Table 2: Pharmaceutical properties of prepared donepezil $\mathrm{HCl}$ intranasal mucoadhesive microsphere formulations.

\begin{tabular}{|c|c|c|c|c|c|c|}
\hline $\begin{array}{l}\text { Formulation } \\
\text { code }\end{array}$ & $\begin{array}{c}\text { Production } \\
\text { yield } \\
(\% \pm S D)\end{array}$ & $\begin{array}{l}\text { Drug loading } \\
\quad(\% \pm \mathrm{SD})\end{array}$ & $\begin{array}{c}\text { Entrapment } \\
\text { efficiency } \\
(\% \pm \text { SD })\end{array}$ & $\begin{array}{l}\text { Particle size } \\
(\mu \mathrm{m} \pm \mathrm{SD})\end{array}$ & $\begin{array}{l}\% \text { Swelling } \\
(\% \pm \text { SD })\end{array}$ & $\begin{array}{l}\text { Mucoadhesion } \\
(\% \pm \text { SD })\end{array}$ \\
\hline Ni & $40.26 \pm 0.1$ & $74.60 \pm 0.01$ & $34.5 \pm 1.02$ & $17.3 \pm 0.3$ & $82 \pm 0.1$ & $45.6 \pm 0.1$ \\
\hline N2 & $44.83 \pm 0.3$ & $64.62 \pm 0.01$ & $40.5 \pm 0.15$ & $14.3 \pm 0.2$ & $83 \pm 0.2$ & $57.6 \pm 0.2$ \\
\hline $\mathrm{N}_{3}$ & $50.45 \pm 0.2$ & $57.77 \pm 0.02$ & $42.3 \pm 0.15$ & $17.6 \pm 0.1$ & $88 \pm 0.1$ & $62.2 \pm 0.1$ \\
\hline $\mathrm{N}_{4}$ & $55.93 \pm 0.1$ & $49.21 \pm 0.03$ & $53.6 \pm 0.21$ & $18.3 \pm 0.5$ & $91 \pm 0.1$ & $79.6 \pm 0.1$ \\
\hline
\end{tabular}

\section{Entrapment efficiency}

The entrapment efficiency of mucoadhesive microsphere formulations lies in the range of 34.5 to $53.6 \%$ (Table 2). The entrapment efficiency was recognized to increase with an enhancement of polymeric concentration. The reason for the enhanced entrapment efficiency with increasing polymer amount may be explained as; an enhanced rate of drug entrapment owing to faster hardening of the larger particles which allows reduced time for the diffusion of the drug out of the particles, thereby leading to high encapsulation efficiency with increasing polymer levels in the formulations.
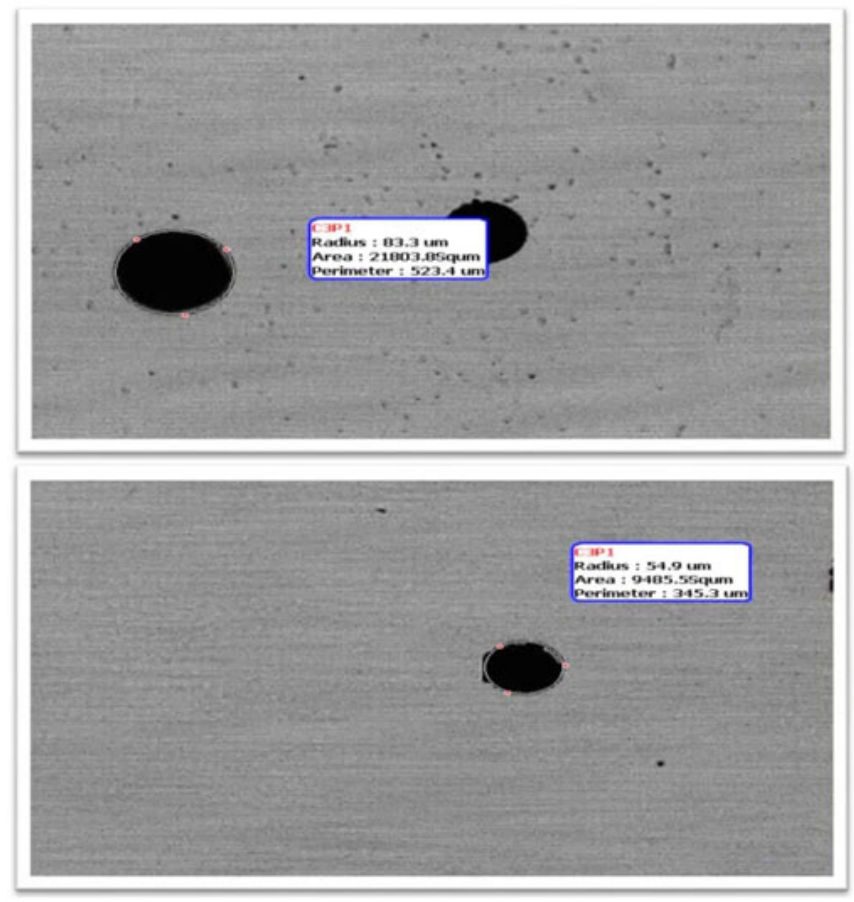

Figure 2: Microscopic image of microspheres.

\section{Particle size}

For intranasal administration of microspheres, the average particle size of the particles must remain in the range of 10 to $20 \mu \mathrm{m}$. The average particle size of the prepared microspheres ranged from $14.3 \mu \mathrm{m}$ to $18.3 \mu \mathrm{m}$ (Table 2) with an average perimeter of $500 \mu \mathrm{m}$, average radius of $75 \mu \mathrm{m}$, and average area of 20,000 square $\mu \mathrm{m}$ (Figure 2). The particle size mainly depends on the rate of stirring; hence, as the stirring rate increases, the particle size decreased, irrespective of the concentration of mucoadhesive polymer. In contrast to the spray drying method where the diameter of the nozzle plays a vital role in the determination of the particle size
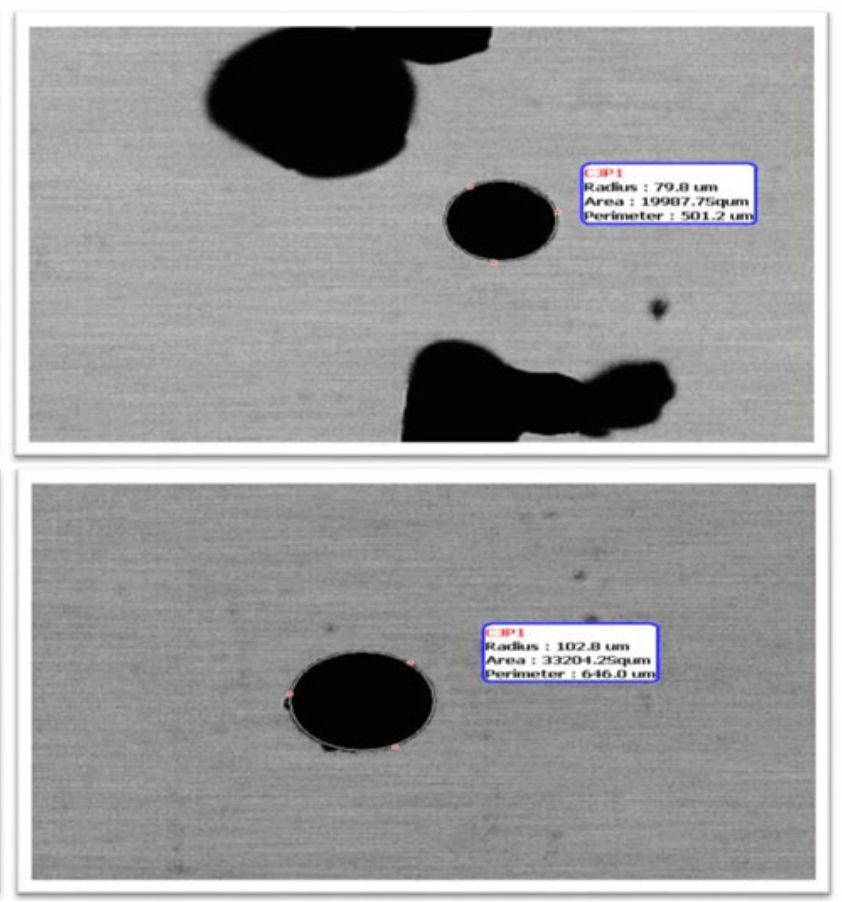
of the formulation, the stirring process plays a critical role in controlling the particle size of formulation in the case of emulsification cross-linking technique.

\section{Swelling property}

The swelling property of the fabricated mucoadhesive microsphere was seen to lie in the range of $82 \%$ to $91 \%$ (Table 2). All the microsphere formulations (N1-N4) swelled rapidly in the Simulated Nasal Fluid (SNF). The swelling capacity of the prepared microspheres was estimated by the amount of polymeric content. With an augmentation in the concentration of polymer (gellan gum), the amount of swelling enhances concurrently due to the retention of fluid (water) by the polymeric matrix.

\section{Mucoadhesion potential}

To make certain the adhesion of formulation to the mucosal membrane at the site of absorption for a prolonged time period, the in vitro mucoadhesion study was performed. The study revealed that all the mucoadhesive microsphere formulations adhered to the nasal mucosal membrane for a prolonged duration. From all batches, the percentage of the originally applied mass of microspheres attached to the nasal mucosa ranged from about $45.6 \%$ to $79.6 \%$ (Table 2). With an increase in the concentration of polymer (gellan gum) from 1:1 ratio to $1: 4$

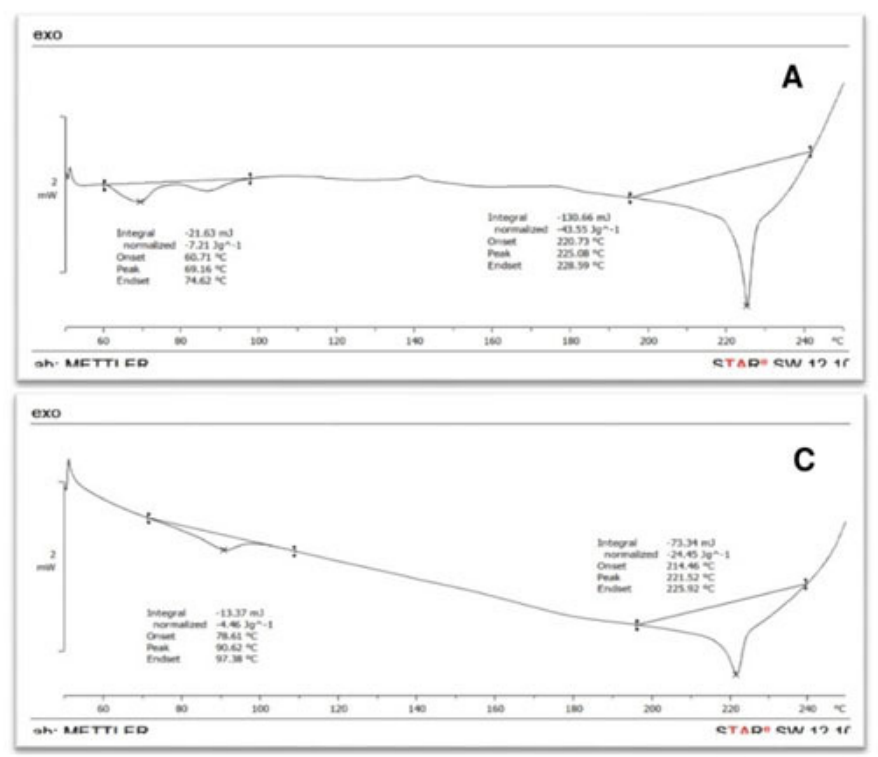

Figure 3: DSC thermograms: (A) pure donepezil $\mathrm{HCl}$; (B) gellan gum; (C) physical mixture; and (D) optimized formulation N2.

\section{Physical state examination}

The X-ray diffraction studies of pure drug, polymer, and optimized formulation N2 are presented in Figure 4. Donepezil $\mathrm{HCl}$, the pure drug represented a crystalline nature with characteristic peaks at $6.64^{\circ}, 6.87^{\circ}$, and $13.00^{\circ}$ on $2 \theta$ scale (Figure 4A). The polymer gellan gum showed no characteristic crystalline peak in the diffractogram which represented ratio, the degree of microsphere mucoadhesion on goat nasal mucosa was perceived. The reason may be the availability of a high quantity of polymeric content for possible contact with the nasal mucosa membrane in the nasal cavity.

\section{Thermal characteristics}

The DSC thermogram of the pure drug, polymer, physical mixture, and optimized formulation (N2) are depicted in Figure 3. Donepezil $\mathrm{HCl}$, the pure drug represented a sharp melting endotherm peak at $225.08^{\circ} \mathrm{C}$ in the thermogram, which corresponds with the melting point of the drug (Figure 3A). The polymer gellan gum demonstrated a broad endotherm peak at $55.64^{\circ} \mathrm{C}$ in the thermogram (Figure 3B). The physical mixture of both donepezil $\mathrm{HCl}$ along with the polymer gellan gum presented the appearance of both the components (sharp endotherm peak at $221.52^{\circ} \mathrm{C}$ for donepezil $\mathrm{HCl}$ and broad endotherm peak at $90.62^{\circ} \mathrm{C}$ for gellan gum) in the thermogram which indicated that the drug and the polymer were compatible with each other (Figure 3C). However, in the thermogram of the optimized mucoadhesive microsphere formulation $\mathrm{N} 2$, the sharp peak shifted towards lower magnitude and a very broad endothermic peak was perceived at $69.16^{\circ} \mathrm{C}$ which indicated that the drug was molecularly dispersed (high disordered amorphous state) inside the microsphere formulation (Figure 3D).

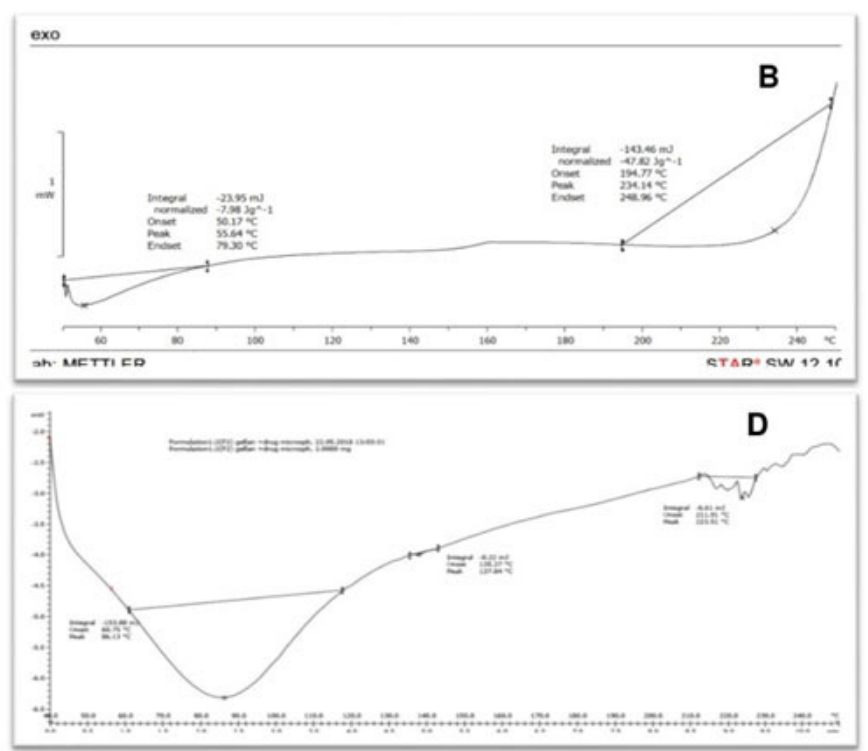

an amorphous nature of the component (Figure 4B). The absence of sharp crystalline peaks of donepezil $\mathrm{HCl}$ loaded mucoadhesive microspheres confirmed that the drug was molecularly dispersed in the polymeric matrix and the drug gets converted into the highly disordered amorphous form (Figure 4C). 


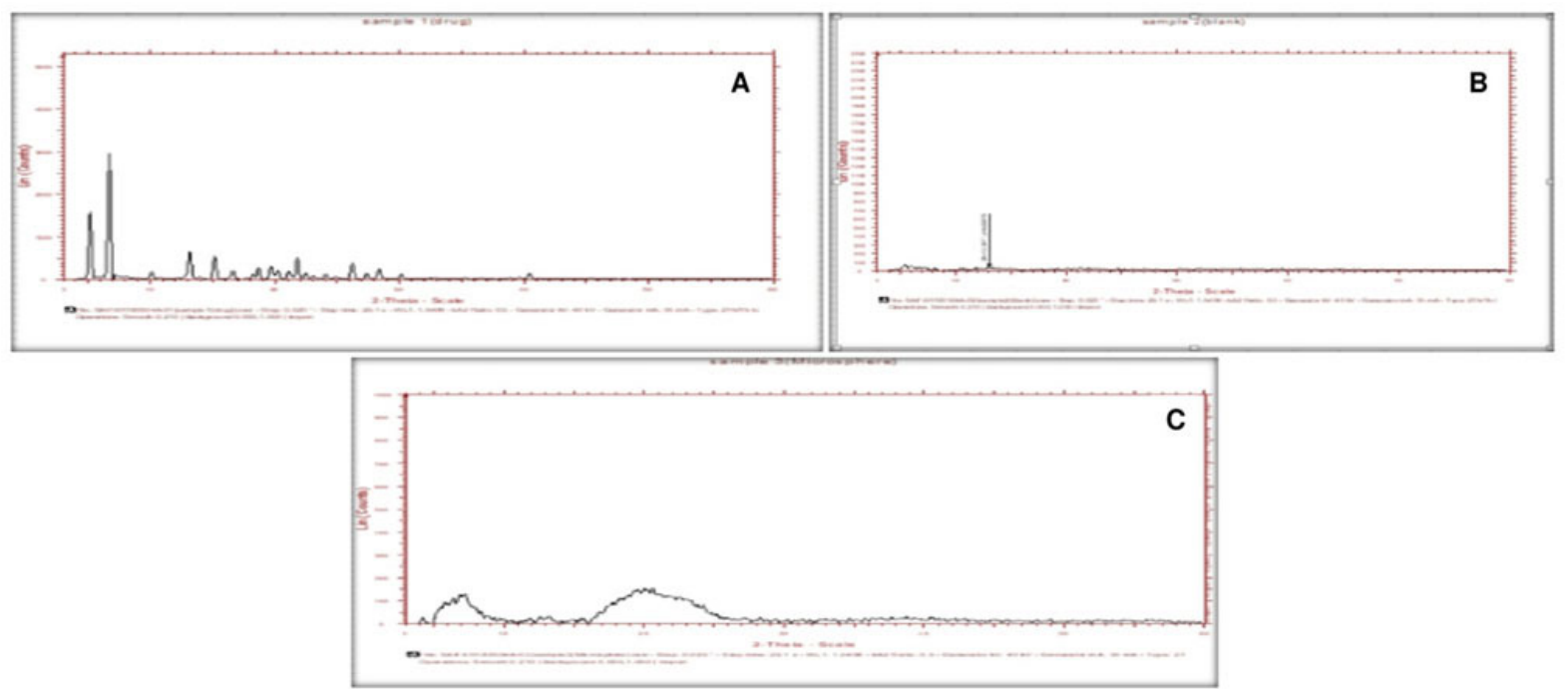

Figure 4: Powder X-Ray diffractogram: (A) pure donepezil HCl; (B) gellan gum; and (C) optimized formulation N2.

\section{Morphological examination}

The morphological characteristics and surface characteristics were studied by SEM where the photomicrographs demonstrated that the microspheres are uniformly circular and round in shape (Figure 5A). The surface of the microspheres has majority smooth surface with minute rough or uneven texture (Figure 5B). No pores or holes or rupture over the formulation surface were perceived which will lead to good deposition, higher retention and slow clearance in the nasal cavity (Figure 5C). No drug particles have been seen to be attached on the surface of the microspheres which represented encapsulation of donepezil $\mathrm{HCl}$ in the polymeric matrix (Figure 5D).

\section{In-vitro release of donepezil HCI}

The drug release profiles from various mucoadhesive microsphere formulation batches (N1-N4) are described in Figure 6A. The formulation $\mathrm{N} 2$ presented the highest cumulative drug release of $98.26 \%$ within $5 \mathrm{hrs}$ duration of in vitro dissolution study (Table 3). The high release may be explained due to the most favorable blend in the polymer concentration that provided an optimized release of donepezil $\mathrm{HCl}$. In contrast to it, the formulation $\mathrm{N} 4$ having a 1:4 ratio represented the lowest release rate after $300 \mathrm{~min}$ of dissolution study. The reason for the decreased release rate may be due to a high concentration of the polymer (gellan gum) which provided controlled release attributes to the microsphere system

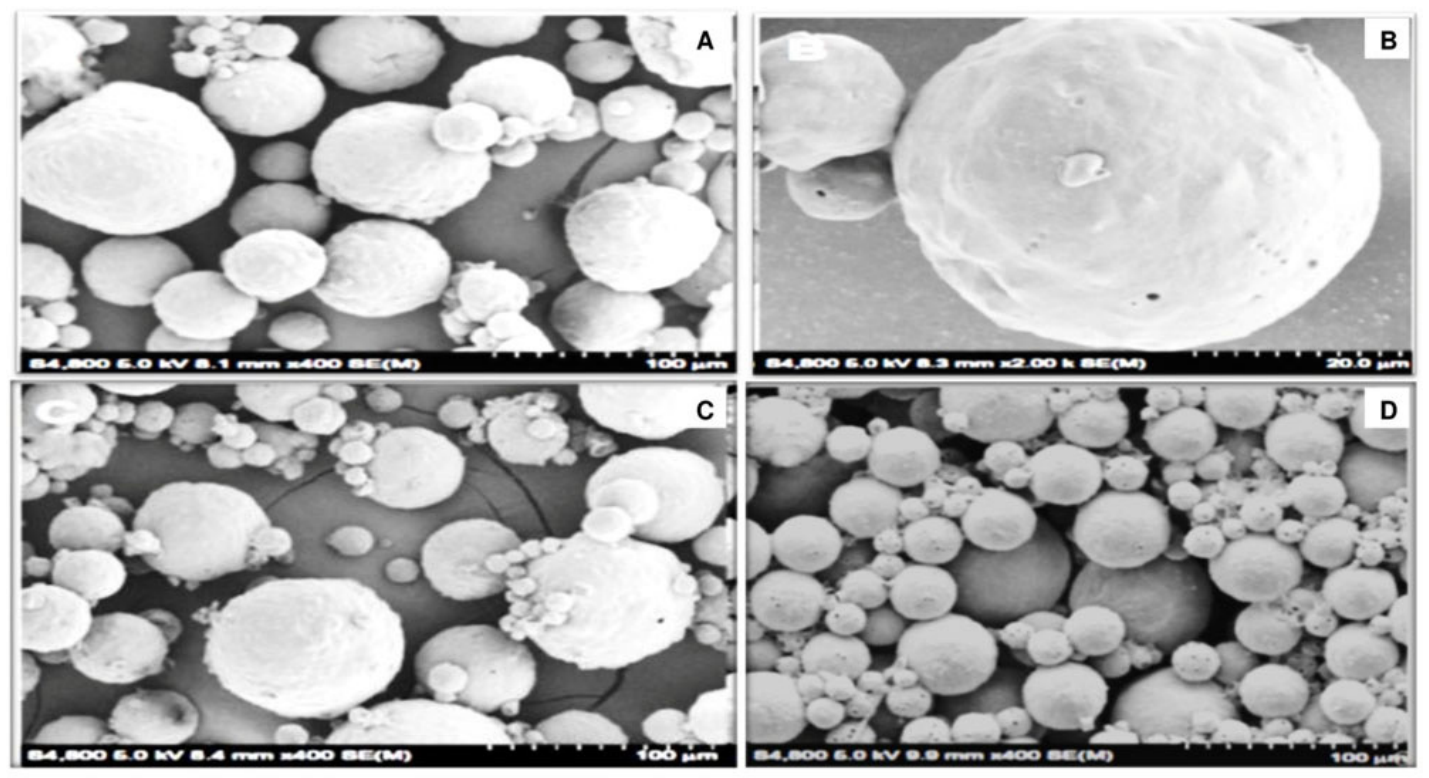

Figure 5: Scanning electron photomicrographs: (A) 400x maginification; (B) 2000x maginification; (C) 400x maginification; and (D) 400x maginification. 


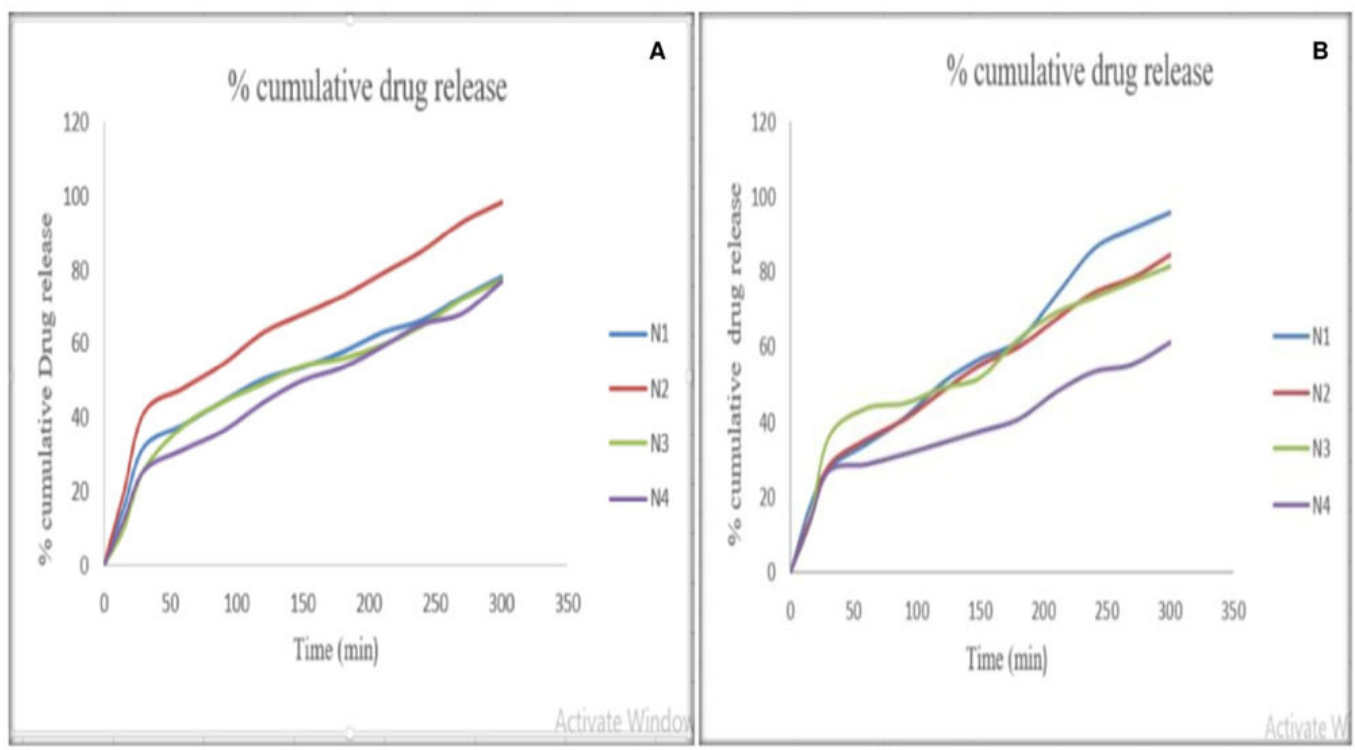

Figure 6: Drug release attributes: $(A)$ in vitro and $(B)$ ex vivo.

Table 3: In vitro drug release profile of donepezil $\mathrm{HCl}$ intranasal mucoadhesive microsphere formulations.

\begin{tabular}{|c|c|c|c|c|}
\hline $\begin{array}{l}\text { Time } \\
\text { (min) }\end{array}$ & $\begin{array}{c}\mathrm{N1}_{1} \\
(\% \pm \mathrm{SD})\end{array}$ & $\begin{array}{c}\mathrm{N}_{2} \\
(\% \pm \mathrm{SD})\end{array}$ & $\begin{array}{c}\mathrm{N}_{3} \\
(\% \pm \mathrm{SD})\end{array}$ & $\begin{array}{c}\mathrm{N}_{4} \\
(\% \pm \mathrm{SD})\end{array}$ \\
\hline 15 & $15.52 \pm 0.1$ & $19.69 \pm 0.1$ & $9.78 \pm 0.3$ & $12.07 \pm 0.2$ \\
\hline 30 & $31.93 \pm 0.1$ & $41.20 \pm 0.1$ & $25.67 \pm 0.2$ & $25.55 \pm 0.1$ \\
\hline 60 & $38.07 \pm 0.2$ & $47.92 \pm 0.3$ & $37.71 \pm 0.1$ & $31.29 \pm 0.1$ \\
\hline 90 & $44.43 \pm 0.1$ & $54.48 \pm 0.1$ & $44.16 \pm 0.2$ & $36.39 \pm 0.5$ \\
\hline 120 & $50.39 \pm 0.1$ & $62.94 \pm 0.1$ & $49.11 \pm 0.1$ & $44.05 \pm 0.1$ \\
\hline 150 & $53.72 \pm 0.2$ & $67.94 \pm 0.2$ & $53.93 \pm 0.4$ & $50.09 \pm 0.2$ \\
\hline 180 & $57.81 \pm 0.2$ & $72.86 \pm 0.1$ & $55.93 \pm 0.4$ & $53.61 \pm 0.1$ \\
\hline 210 & $63.06 \pm 0.2$ & $79.03 \pm 0.1$ & $59.58 \pm 0.5$ & $59.27 \pm 1.1$ \\
\hline 240 & $66.41 \pm 0.1$ & $85.07 \pm 0.2$ & $64.79 \pm 0.1$ & $65.31 \pm 0.1$ \\
\hline 270 & $72.62 \pm 0.2$ & $92.87 \pm 0.3$ & $71.97 \pm 0.2$ & $68.16 \pm 0.2$ \\
\hline 300 & $78.24 \pm 0.1$ & $98.26 \pm 0.1$ & $77.21 \pm 0.1$ & $76.92 \pm 0.1$ \\
\hline
\end{tabular}

and relatively restricted the free release of donepezil $\mathrm{HCl}$ in the media. For examining the drug release mechanism, the release data obtained in the case of optimized formulation N2 were fitted to various kinetic models such as zero-order, first-order, Higuchi's plot, and Korsmeyer-Peppas exponential model.

\section{Ex vivo permeation of donepezil HCI}

The ex vivo permeation study was performed using the goat nasal mucosa for various batches of mucoadhesive formulation (Figure 6B). The formulation N1 presented the highest cumulative drug release of $95.73 \%$ within 5 hrs duration of ex vivo dissolution study (Table 4). The reason for higher release as compared to other formulations may be due to low polymeric content that facilitated the faster release of donepezil $\mathrm{HCl}$. The formulation $\mathrm{N} 4$ having a 1:4 ratio represented the lowest release rate after 300 min of dissolution study. The reason for the decreased release rate may be due to a high concentration of the polymer (gellan gum) which provided controlled release attributes to the microsphere system and relatively restricted the free release of donepezil $\mathrm{HCl}$ in the media.

\section{Kinetic proffles of drug release}

The analysis of the ex-vivo drug release data indicates that donepezil $\mathrm{HCl}$ release from formulations $\mathrm{N} 1$ and $\mathrm{N} 4$ followed zero-order kinetics whereas the formulations N2 and N3 followed the Higuchi's plot as observed from the correlation coefficient ' $r$ ' values (Table 5). The results indicated that the drug releases from the microspheres at a constant rate in the case of N1 and N4. 
Table 4: Ex vivo drug release profile of donepezil $\mathrm{HCl}$ intranasal mucoadhesive microsphere formulations.

\begin{tabular}{lcccc}
$\begin{array}{l}\text { Time } \\
(\mathrm{min})\end{array}$ & $\begin{array}{c}\mathrm{N} \text { ( } \\
(\% \pm \mathrm{SD})\end{array}$ & $\begin{array}{c}\mathrm{N}_{2} \\
(\% \pm \mathrm{SD})\end{array}$ & $\begin{array}{c}\mathrm{N}_{3} \\
(\% \pm \mathrm{SD})\end{array}$ & $\begin{array}{c}\mathrm{N}_{4} \\
(\% \pm \mathrm{SD})\end{array}$ \\
\hline 15 & $17.28 \pm 0.1$ & $14.28 \pm 0.1$ & $13.21 \pm 0.1$ & $12.76 \pm 0.2$ \\
30 & $27.58 \pm 0.2$ & $28.15 \pm 0.1$ & $35.76 \pm 0.1$ & $26.61 \pm 0.1$ \\
60 & $34.03 \pm 0.2$ & $35.23 \pm 0.2$ & $43.45 \pm 0.2$ & $28.45 \pm 0.1$ \\
90 & $40.99 \pm 0.1$ & $40.53 \pm 0.2$ & $44.78 \pm 0.1$ & $31.15 \pm 0.1$ \\
120 & $50.36 \pm 0.3$ & $48.09 \pm 0.1$ & $48.87 \pm 0.1$ & $34.15 \pm 0.1$ \\
150 & $56.78 \pm 0.2$ & $55.08 \pm 0.3$ & $51.71 \pm 0.5$ & $37.23 \pm 0.5$ \\
180 & $61.47 \pm 0.5$ & $59.83 \pm 0.4$ & $61.91 \pm 0.2$ & $40.39 \pm 0.2$ \\
210 & $73.7 \pm 0.1$ & $67.27 \pm 0.1$ & $73.98 \pm 0.3$ & $47.66 \pm 0.3$ \\
240 & $86.18 \pm 0.2$ & $74.40 \pm 0.1$ & $77.22 \pm 0.2$ & $53.08 \pm 0.1$ \\
270 & $91.36 \pm 0.1$ & $78.20 \pm 0.2$ & $81.31 \pm 0.1$ & $54.93 \pm 0.1$ \\
300 & $95.73 \pm 0.1$ & $84.40 \pm 0.1$ & & $60.76 \pm 0.2$ \\
\hline
\end{tabular}

Table 5: Results of kinetic models applied to release profile of various microsphere formulations.

\begin{tabular}{lccccc} 
Formulation Code & Zero order & First order & Higuchi Model & $\begin{array}{c}\text { Korsmeyer-Peppas } \\
\text { Model }\end{array}$ & Best fit model \\
N1 & 0.98 & 0.58 & 0.96 & 0.39 & Zero order \\
$N_{2}$ & 0.97 & 0.54 & 0.99 & 0.33 & Higuchi model \\
$N_{3}$ & 0.92 & 0.47 & 0.96 & 0.28 & Higuchi model \\
$N_{4}$ & 0.97 & 0.62 & 0.93 & 0.21 & Zero order \\
\hline
\end{tabular}

\section{Effect of microspheres on nasal vasculature}

The histopathological investigations of hematoxylin-eosin stained untreated goat nasal mucosa showed the presence of normal goblet cells and ciliated respiratory epithelium.
In contrast to it, goat nasal mucosa treated with optimized drug-loaded microsphere formulation N2 presented no deleterious response or adverse effects over the nasal mucosa (Figure 7).
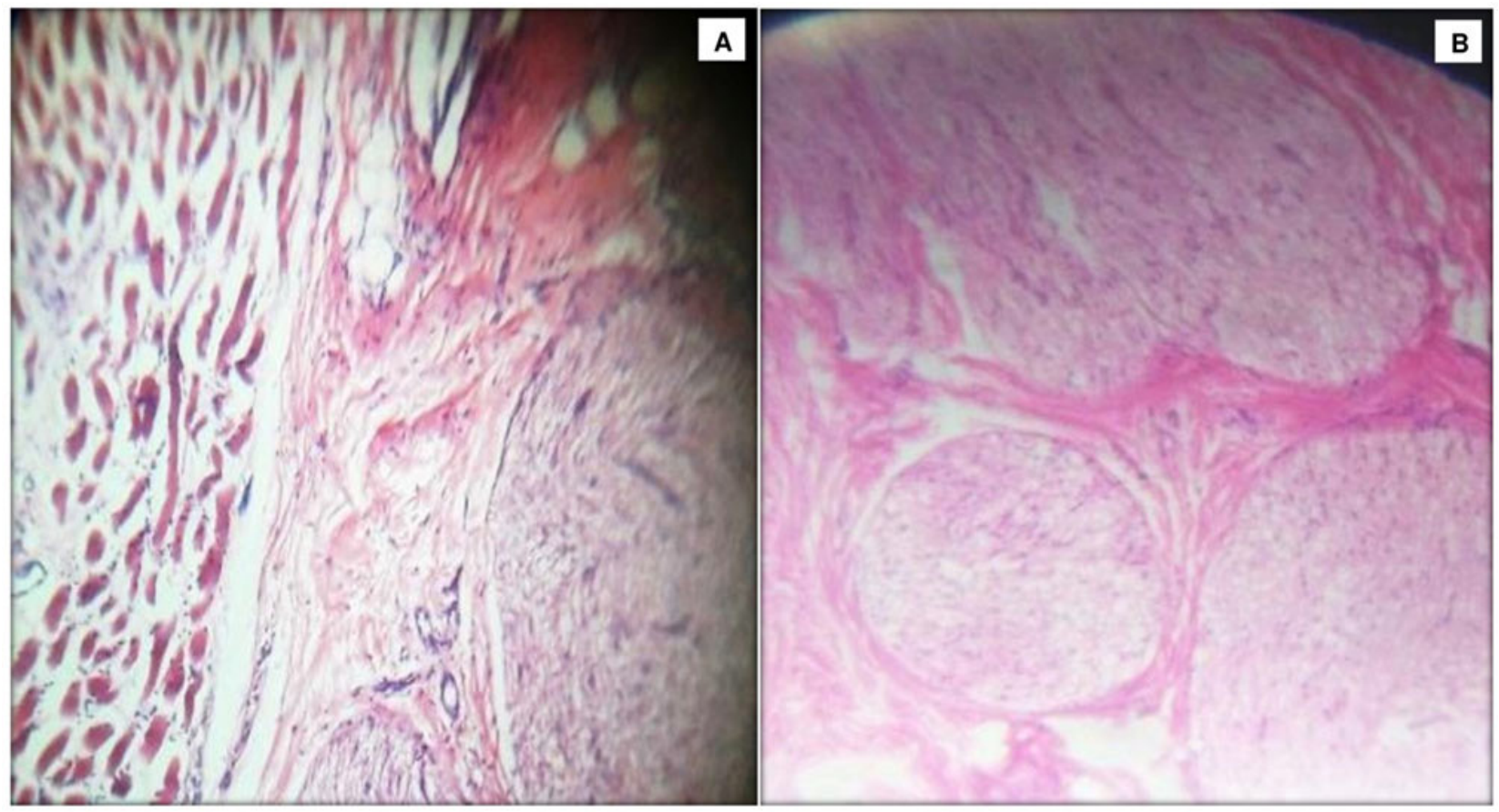

Figure 7: Histopathological studies: (A) Untreated goat mucosa; (B) drug-loaded microspheres treated goat mucosa. 


\section{CONCLUSION}

The present research involved emulsification cross-linking technique assisted development of gellan gum-based intranasal mucoadhesive microspheres loaded with donepezil $\mathrm{HCl}$ for possible drug delivery in the promising treatment of Alzheimer's disease as compared to the conventional dosage forms such as tablets or capsules. The fabricated intranasal microspheres had good spherical nature and excellent swelling property with entirely smooth surfaces. After reaching the nasal mucosa, the mucoadhesive microspheres formulations come in contact with the nasal fluid (containing cations), spontaneous viscous gelation (decreases the clearance rate) occurs in the nasal cavity, and the activity enhances several-folds by elevating the residence duration. The histopathological investigation revealed that the polymer was biocompatible and did not produce any toxic effects in the nasal mucosa after administration for prolonged periods.

\section{ACKNOWLEDGEMENT}

The authors are thankful to the Dadasaheb Balpande College of Pharmacy management for providing research facilities and support for performing this study.

\section{Conflict of Interest}

No conflict of interest is declared regarding the publication of this manuscript.

\section{Funding Information}

No funding is associated with this work.

\section{REFERENCES}

1. Mahapatra DK, Bharti SK. Drug Design. New Delhi: Tara Publications Private Limited, 2016.

2. Mahapatra DK, Shivhare RS. Medicinal Chemistry-II. Nagpur: ABD Publications Private Limited, 2019.

3. Mahapatra DK, Bharti SK. Medicinal Chemistry with Pharmaceutical Product Development. New Jersey: Apple Academic Press, 2019.

4. Chhajed SS, Bastikar V, Bastikar AV, Mahapatra DK. Computer Aided Drug Design. Pune: Everest Publishing House, 2019.

5. Mahapatra DK, Bharti SK. Handbook of Research on Medicinal Chemistry: Innovations and Methodologies. New Jersey: Apple Academic Press, 2017.

6. Chhajed SS, Upasani CD, Wadher SJ, Mahapatra DK. Medicinal Chemistry. Nashik: Career Publications Private Limited, 2017.
7. Appasaheb PS, Manohar SD, Bhanudas SR, Anjaneri N. A review on intranasal drug delivery system. J Adv Pharm Edu Res. 2013;3(4):333-346.

8. Pires A, Fortuna A, Alves G, Falcão A. Intranasal drug delivery: how, why and what for?. J Pharm Pharm Sci. 2009;12(3):288311.

9. Bhise SB, Yadav AV, Avachat AM, Malayandi R. Bioavailability of intranasal drug delivery system. Asian J Pharm. 2014;2(4):201-215.

10. Pereswetoff-Morath L. Microspheres as nasal drug delivery systems. Adv Drug Deliv Rev. 1998;29(1-2):185-194.

11. Vajdy M, O'Hagan DT. Microparticles for intranasal immunization. Adv Drug Deliv Rev. 2001;51(1-3):127-141.

12. Kulkarni K, Bhambere T, Chaudhary G, Talele S, Moghal R. Brain targetting through intranasal route. Brain. 2013;5(4):14411450 .

13. Mistri PA, Patel DJ, Prajapati JJ. Intranasal drug delivery system: a review. Int J Pharm Innov. 2012;2(2):43-55.

14. Abbas Z, Swamy NG. Mucoadhesive microspheres as intranasal drug delivery systems: A review. Indian Drugs. 2012;49(1):5-23.

15. Mahajan NM, Pardeshi A, Mahapatra DK, Darode A, Dumore NG. Hypromellose and Carbomer induce bioadhesion of Acyclovir tablet to vaginal mucosa. Indo Am J Pharm Res. 2017;7(12):1108-1118.

16. Khan S, Gangane PS, Mahapatra DK, Mahajan NM. Natural and Synthetic Polymers assisted Development of Lurasidone Hydrochloride Intranasal Mucoadhesive Microspheres. Indian J Pharm Edu Res. 2020;54(1):213-222.

17. Godbole MD, Mahapatra DK, Khode PD. Fabrication and Characterization of Edible Jelly Formulation of Stevioside: A Nutraceutical or OTC Aid for the Diabetic Patients. Inventi Rapid: Nutraceut. 2017;2017(2):1-9.

18. Umaredkar A, Dangre PV, Mahapatra DK, Dhabarde DM. Fabrication of chitosan-alginate polyelectrolyte complexed hydrogel for controlled release of cilnidipine: A statistical design approach. Mater Technol. 2018;1:1-11.

19. Dangre PV, Godbole MD, Ingle PV, Mahapatra DK. Improved Dissolution and Bioavailability of Eprosartan Mesylate Formulated as Solid Dispersions using Conventional Methods. Indian J Pharm Edu Res. 2016;50(3):S209-S217.

20. Sonkusre N, Dhabarde DM, Mahapatra DK. Formulation and development of mirtazapine self emulsifying drug delivery system (SEDDS) for enhancement of dissolution profile. Inventi Impact: NDDS. 2016;2016(4):155-163.

21. Mahajan NM, Wadhwane P, Mahapatra DK. Rational designing of sustained release matrix formulation of Etodolac employing Hypromellose, Carbomer, Eudragit and Povidone. Int J Pharm Pharm Sci. 2017;9(12):92-97.

22. Mahajan NM, Zode GH, Mahapatra DK, Thakre S, Dumore NG, Gangane PS. Formulation development and evaluation of transdermal patch of piroxicam for treating dysmenorrhoea. J Appl Pharm Sci. 2018;8(11):35-41.

23. Dhawale P, Mahajan NM, Mahapatra DK, Mahajan UN, Gangane PS. HPMC K15M and Carbopol 940 mediated fabrication of ondansetron hydrochloride intranasal mucoadhesive microspheres. J Appl Pharm Sci. 2018;8(8):75-83. 